\title{
EXPANSÃO DA EDUCAÇÃO SUPERIOR NO INSTITUTO FEDERAL DE EDUCAÇÃO, CIÊNCIA E TECNOLOGIA DA PARAÍBA: OS DELINEAMENTOS NO PERÍODO 2008- 2015
}

\author{
M. S. V. ARAÚJO ${ }^{1}$, A. CABRAL NETO ${ }^{2}$ \\ Instituto Federal de Educação, Ciência e Tecnologia da Paraíba ${ }^{1}$, Universidade Federal do Rio Grande do Norte ${ }^{2}$ \\ maizesousavirgolino@gmail.com ${ }^{1}$ \\ ORCID ID: https://orcid.org/0000-0003-0978-3702 ${ }^{1}$
}

DOI: $10.15628 /$ holos.2020.9903

\section{RESUMO}

O artigo tem por objetivo discutir o processo de expansão da educação superior no Instituto Federal de Educação, Ciência e Tecnologia da Paraíba (IFPB), verticalizando a análise em três dos seus maiores campi (João Pessoa, Campina Grande e Sousa). Para viabilizar a análise da temática foram utilizadas informações registradas em documentos oficiais do período 2008-2015 e dados disponíveis no sítio da instituição sobre o processo de expansão da Educação Superior. Conclui-se que o movimento de expansão do IFPB, em termos de ampliação no número de campi, proporcionou o alcance das metas estabelecidas nos três Planos de Desenvolvimento Institucionais (PDIs) relativos aos anos de 2005, 2010 e 2015, viabilizando um crescimento de
$600 \%$ no período de 2005-2015. Esse aumento do número de campi oportunizou a interiorização da rede de educação profissional e tecnológica na Paraíba. O movimento de expansão da graduação do IFPB, embora siga a lógica do novo padrão de modernização para a Educação Superior, incluso no novo paradigma de produção capitalista neoliberal que incentiva a adoção de mecanismos gerenciais e as parcerias com empresas privadas, contraditoriamente, traz elementos de alcance social, pois a instituição permitiu uma ampliação substancial da oferta e da interiorização de cursos de Educação Superior em todo o estado da Paraíba para setores historicamente excluído desse nível educacional

Palavras-chave: Educação Superior, Expansão, IFPB.

\section{HIGHER EDUCATION EXPANSION'S AT THE INSTITUTO FEDERAL DE EDUCAÇÃO, CIÊNCIA E TECNOLOGIA DA PARAÍBA (IFPB) [FEDERAL INSTITUTE OF EDUCATION, SCIENCE AND TECHNOLOGY OF PARAÍBA]: OUTLINES IN THE TIME FRAME OF 2008- 2015}

\begin{abstract}
This article aims to discuss the expansion process of higher education in the Instituto Federal de Educação, Ciência e Tecnologia da Paraíaba (IFPB) [Federal Institute of Education, Science, and Technology of Paraíba] (IFPB), narrowing the analysis in the three biggest campi (João Pessoa, Campina Grande e Sousa). To make the thematic analysis viable, the research was based on information extracted from official documents from the period of 2008 to 2015, combined with data available on the institution's website. The conclusion was that the expansion movement on IFPB (the growth of campi's numbers) granted the achievement of the goals established in 2005, 2010 and 2015's Institutional Development Plan. Thus, it Keywords: Higher Education, Expansion, IFPB.
\end{abstract}

enabled a $600 \%$ raise from the period of 2005 to 2015 , also, it provided access to professional education on the inland of Paraíba. The expansion movement of IFPB's higher education system, despite following the logic of the new modernization standard for Higher Education included in the new paradigm of neoliberal capitalist production - which encourages the adoption of managerial mechanisms and partnerships with private companies - brought elements of social reach, as it allowed a great expansion on the offer of higher education courses to sectors historically excluded from that educational level. 


\section{APRESENTAÇÃO}

Neste artigo, objetiva-se compreender o processo de expansão da educação superior do Instituto Federal de Educação, Ciência e Tecnologia da Paraíba (IFPB), reunindo uma série de dados em relação à expansão de seus campi e de seus cursos de graduação, em uma análise a partir dos documentos institucionais e de dados disponíveis no sítio da instituição. $\mathrm{O}$ artigo reúne uma série histórica de informações e dados internos à instituição sobre o processo de expansão da Educação Superior - cursos de graduação, congregando, desta forma, um conjunto de documentos e informações relacionais que compõem o processo empírico da expansão da Educação Superior no IFPB no período entre 2008 e 2015, com realce para os campi de João Pessoa, Campina Grande e Sousa.

$\mathrm{Na}$ análise da temática foram consideradas fontes primárias e secundárias. A pesquisa documental (fonte primária) teve como referência documentos do MEC, indicativos da expansão da Educação Superior nos Institutos Federais de Educação, a exemplo da lei de criação dos IFs e documentos internos ao IFPB, dos quais destacam-se os Planos de Desenvolvimento Institucionais (PDIs) com duração de quatro anos, que definem a missão, os objetivos, as metas e as estratégias de crescimento institucional. Foram analisados três PDIs do IFPB referentes, respectivamente, aos anos de 2005-2009, 2010-2014 e de 2015-2019.

Sobre as fontes secundárias, foram utilizados dados do Instituto Nacional de Pesquisas Educacionais Anísio Teixeira - MEC/INEP - Sinopses Estatísticas da Educação Superior - graduação (2000; 2005; 2008; 2009; 2010; 2011; 2012; 2013; 2014; 2015), além de dados divulgados pelo MEC por meio da Secretaria de Educação Profissional e Tecnológica (Setec) sobre a expansão dos Institutos Federais de Educação no país, entre os anos de 2005/2008 a 2016.

\section{EDUCAÇÃO SUPERIOR NO IFPB: O CENÁRIO DE EXPANSÃO DE CAMPI, CURSOS E MATRÍCULAS}

No início do ano de 2008, o $\operatorname{IFPB}^{1}$ ainda era denominado de Centro Federal de Educação Tecnológica (CEFET) e contava, apenas, com três Unidades de Ensino Descentralizadas (UNEDs) em todo o estado da Paraíba - João Pessoa (1909), Cajazeiras (2004) e Campina Grande (2007). Foi ainda como CEFET-PB, no ano de 1999, que o IFPB registrou a oferta de seu primeiro curso superior de graduação - Tecnólogo em Telemática - no campus de João Pessoa, quando houve sua transformação de Escola Técnica Federal de Educação da Paraíba para Centro Federal de Educação da Paraíba.

\footnotetext{
10 atual Instituto Federal de Educação, Ciência e Tecnologia da Paraíba tem mais de cem anos de existência. Ao longo de todo esse período, recebeu diferentes denominações: Escola de Aprendizes Artífices da Paraíba - de 1909 a 1937; Liceu Industrial de João Pessoa - de 1937 a 1961; Escola Industrial "Coriolano de Medeiros" ou Escola Industrial Federal da Paraíba - de 1961 a 1967; Escola Técnica Federal da Paraíba - de 1967 a 1999; Centro Federal de Educação Tecnológica da Paraíba - de 1999 a 2008; e, finalmente, Instituto Federal de Educação, Ciência e Tecnologia, com a edição da Lei 11.892 de 29 de dezembro de 2008, que instituiu a Rede Federal de Educação Profissional e Tecnológica, criou os Institutos Federais de Educação (IFEs), atribuindo a estes o status de Instituição de Nível Superior - IES.
} 
Nesse mesmo ano a Escola Agrotécnica de Sousa se caracterizava como uma instituição independente do CEFET-PB e estava organizada em três unidades complementares dentro do próprio município de Sousa (PDI, 2015). Foi somente a partir de 29 de dezembro de 2008 (BRASIL, 2008), com a integração dessas duas instituições, que o IFPB apresentou uma nova identidade e uma nova organização estrutural bem mais aproximada ao modelo de universidade, quando transformou a diretoria geral em reitoria, suas unidades em campi e se reorganizou internamente para ampliar a sua oferta de cursos, notadamente, de graduação, necessitando, a partir de então, de ampliar as suas estruturas física e de pessoal.

A mudança de CEFET-PB, no ano de 1999, para IFPB no ano de 2008 , aconteceu no contexto do final da 1a fase de expansão física da educação profissional do país, compreendida entre os anos de 1995 e 2008. No período de 2008 a 2010, foi definida a 2a fase da expansão da educação profissional, em que o IFPB passou de 03 para 09 campi. Nos períodos entre 2010, 2014-2018, denominado de 3a fase da expansão da educação profissional, o IFPB passou de 09 campi para 21 campi distribuídos em todas as regiões do Estado, resultando em um aumento de 12 novos campi. Cabe registrar que a progressão da expansão dos campi do IFPB, entre os anos de 2008 e 2015, inclui não apenas o quantitativo de campi, mas também apresenta a sua interiorização em todo o estado da Paraíba.

Assim, percebe-se que a ampliação dos campi do IFPB se efetivou na capital João Pessoa, atingindo também a região metropolitana, incluindo as cidades de Santa Rita e Cabedelo e o bairro de Mangabeira. A expansão se efetivou, ademais, por meio de processo de interiorização, em todo o estado da Paraíba, alcançando as cidades consideradas polos de desenvolvimento regional do Estado.

A distribuição das cidades de localização de cada campus do IFPB foi definida a partir da delimitação técnica de polos de abrangência demarcados por um raio de 50 quilômetros entre os municípios, principalmente para as cidades do interior, além de estudos que demarcaram a viabilidade de cursos, considerando desde a quantidade da população dos municípios de 25,50 e 100 mil habitantes, dados da indústria e serviços, os quais foram também associados aos arranjos produtivos locais, à missão e aos objetivos sociais da instituição de colaborar com o desenvolvimento da região a partir das potencialidades locais. Essas metas foram e são em sua maioria importantes para a definição dos tipos de cursos técnicos e de graduação ofertados em cada localidade do campus (IFPB, 2010) e são oriundas dos documentos determinados pelo MEC.

O processo de expansão física, em números de campi do IFPB, é uma ação definida como consolidada pelo governo federal e abarca uma relação direta com a expansão da Educação Superior - cursos de graduação - e interiorização dessa instituição. Os 21 campi do IFPB², até o ano de 2018, estão distribuídos geograficamente em 19 cidades da Paraíba.

\footnotetext{
${ }^{2}$ Os 21 campi são: Areia, Cabedelo, Cabedelo Centro, Cajazeiras, Campina Grande, Catolé do Rocha, Esperança, Guarabira, Itabaiana, Itaporanga, João Pessoa, Mangabeira, Monteiro, Patos, Pedras de Fogo, Picuí, Princesa Isabel, Santa Luzia, Santa Rita, Soledade e Sousa.
} 
Dos 21 campi do IFPB, 10 ofertam Educação Superior, quais sejam: João Pessoa, Cabedelo, Itabaiana, Campina Grande, Guarabira, Picuí, Monteiro, Sousa, Cajazeiras e Princesa Isabel, distribuídos em todo o estado da Paraíba, fator que contempla significativa interiorização, totalizando ao todo um percentual de oferta em $48 \%$ dos campi dessa instituição. Desse modo, a oferta da Educação Superior no IFPB, em nível de graduação, embora ainda não tenha atingido a totalidade das unidades, representa uma significativa ampliação, considerando que ela já está presente em quase $50 \%$ de seus campi.

A oferta de Educação Superior no Instituto Federal de Educação, Ciência e Tecnologia da Paraíba, especialmente nos cursos de graduação, dá-se nas três modalidades de cursos bacharelados, tecnólogos e licenciaturas -, totalizando um quantitativo de 38 cursos, até o ano de 2015, distribuídos da seguinte forma: 22 cursos de tecnólogos, 09 cursos de licenciaturas e 07 cursos de bacharelados, conforme dados oficiais do IFPB de 2015. Isso está representado no Gráfico 1, elaborado a partir dos dados do portal do estudante - cursos de graduação do IFPB.

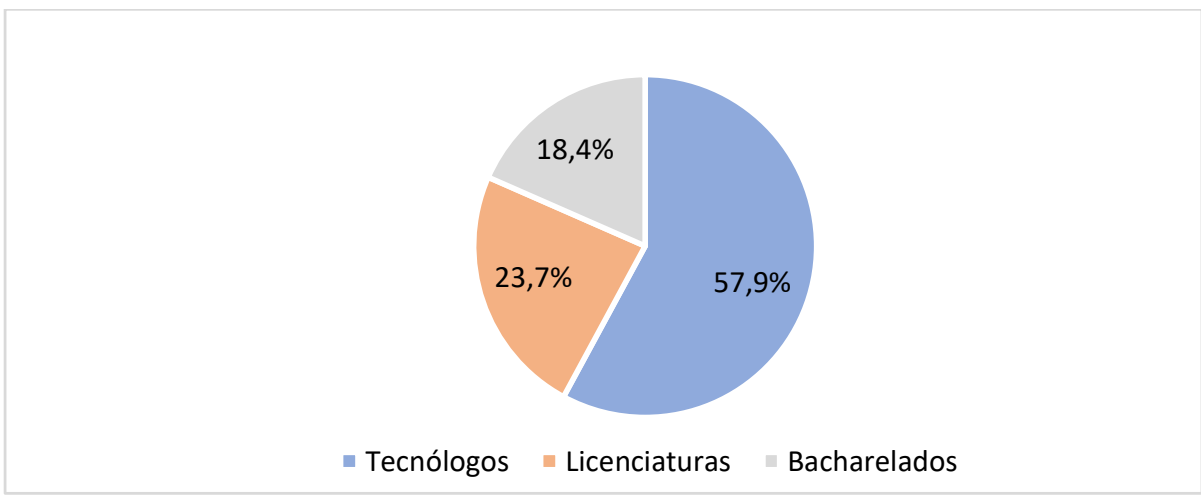

Gráfico 1 - Percentual de oferta por tipologia/modalidade de cursos de graduação no IFPB (2015)

Fonte: Elaboração própria dos autores, a partir dos dados do portal do estudante do IFPB - Cursos de Graduação, 2015.

Os dados do Gráfico 1, mostram que os percentuais de oferta de cursos de graduação do IFPB seguem as mesmas características verificadas nos IFs no panorama nacional, onde se observa a seguinte ordem de prioridade na oferta dos cursos: tecnólogo, licenciatura e bacharelado (BETIN, 2017). No IFPB consta-se, também, a prevalência significativa na oferta de cursos de tecnólogo, com um percentual de $57,9 \%$ da oferta total dos cursos. Eles representam a maior oferta do IFPB desde 1999, condição que reforça o foco dos IFs de preparar os jovens para atender, de forma mais técnica e pontual, a demandas oriundas do setor industrial e do trabalho como um todo, considerando, ainda, as características dos arranjos produtivos locais (APLS). Comparando esse dado do IFPB ao contexto nacional, incluindo todos os IFs, observa-se que os percentuais de maior oferta de cursos, ao contrário do IFPB, estão relacionados aos cursos de bacharelados, seguidos das licenciaturas e, apenas, em terceira e última colocação os cursos de tecnólogos (ARAÚJO, 2019).

Em relação aos cursos de licenciatura oferecidos pelo IFPB, determinados para atender a uma demanda nacional projetada pela falta de professores para atuarem na educação básica (mais 
especificamente nas áreas de ciências e matemática e para a educação profissional), apresentam um percentual geral de oferta de $23,7 \%$ (Gráfico 1), o que confirma que o IFPB ampliou a sua oferta de cursos de licenciatura, consolidando o que determina o artigo 8 ㅇ da lei de criação dos IFs, Lei no 11.892, de 29 de dezembro de 2008, quanto à obrigatoriedade de ofertar, no mínimo, 20\% das vagas anuais da instituição para aos cursos de licenciatura (BRASIL, 2008).

Já os dados relacionados aos cursos de bacharelado registram um percentual de $18,4 \%$ da oferta (Gráfico 1), o que demostra que, a partir de 2015, há uma tendência de ampliação dos bacharelados no Instituto, alguns ocupando, inclusive, o lugar de cursos de tecnólogos, como aconteceu, em 2018, no campus de João Pessoa, com o tecnólogo em Construção de Edifícios, o qual foi extinto para ser ofertado o bacharelado em Engenharia Civil.

O IFPB, como parte do contexto das políticas e reformas educacionais brasileiras, sobretudo, aqueles referentes à educação tecnológica, é incorporado como espaço institucional contributivo de significativa expansão da Educação Superior na rede pública federal de educação do Brasil e, notadamente, no estado da Paraíba. Essa expansão se inicia no ano de 2005 e assume maior visibilidade, no ano de 2015, quando o IFPB amplia a sua oferta para 39 cursos de graduação e, em 2019, para 44 cursos, tendo como uma das estratégias dessa expansão a criação de cursos pela modalidade EaD.

A ampliação e a diversificação da oferta de cursos (técnicos e superiores) no IFPB têm oportunizado a milhares de jovens e adultos acesso aos ensinos técnicos e tecnológicos (cursos de educação básica, técnica e superior), tendo a oferta total de vagas, até 2015 , registrada em um quantitativo de 30.000 matrículas/estudantes, e a oferta de cursos de graduação com o quantitativo de 11.994 estudantes (IFPB, 2017). Isso significa que 39,04 \% do total de vagas preenchidas na instituição foram ocupadas por alunos de cursos de graduação. Os 11.994 alunos matriculados, no ensino superior, em 2015, no IFPB, segundo o Plano Estratégico para Permanência e Êxito dos Estudantes do IFPB 2017-2027 (IFPB, 2017, p. 18-19), estavam assim distribuídos: “Cabedelo (444), Cajazeiras (1.159), Campina Grande (1.331), Guarabira (170), João Pessoa (6.086), Monteiro (745), Patos (472), Picuí (375), Princesa Isabel (310)e Sousa (902)".

Conforme esses dados observa-se que o maior percentual de estudantes da graduação estão matriculados nos campi de João Pessoa (50,74\%) e Campina Grande (11,1\%), o que se justifica tanto pelo fator tempo de funcionamento, para o caso do campus de João Pessoa, quanto pelo tamanho em maior número populacional do município, para os dois campi.

Nesse contexto, registra-se que a expansão dos cursos de graduação no IFPB, conforme Araújo (2019) alcançou todas as metas de expansão em cada um dos campi ofertantes, conseguindo atingir as metas definidas nos Planos de Desenvolvimento Institucional (PDIs) dos anos de 2005, 2010 e 2015. 


\section{EDUCAÇÃO SUPERIOR NOS CAMPI DE JOÃO PESSOA, SOUSA E CAMPINA GRANDE: EXPANSÃO E PARCERIAS}

Esta sessão do artigo procede uma análise do processo de expansão, especificamente, em três campi representativos do IFPB - João Pessoa, Sousa e Campina Grande - que integram o conjunto dos seus 21 campi. Quanto aos seus aspectos econômico, social e político, estão presentes em 3 (três) das 4 (quatro) mesorregiões da Paraíba, assim denominadas, de acordo com a classificação estabelecida pelo IBGE: Mata paraibana (Campus João Pessoa), Agreste paraibano (Campus Campina Grande), e o Sertão paraibano (Campus Sousa).

Em relação a oferta de cursos superiores de graduação nos três campi a situação constatada está registrado na Tabela 1.

Tabela 1 - Percentual de oferta de cursos de graduação nos campi de João Pessoa, Sousa e Campina Grande (2015)

\begin{tabular}{|c|c|c|}
\hline Educação Superior - 10 campi do IFPB & 38 cursos Total geral & $100 \%$ \\
\hline Campus João Pessoa & 14 cursos & $36,84 \%$ \\
\hline Campus Sousa & 7 cursos & $18,42 \%$ \\
\hline Campus Campina Grande & 6 cursos & $15,79 \%$ \\
\hline Total da amostra pesquisada & 27 cursos & $71,1 \%$ \\
\hline
\end{tabular}

Fonte: Elaboração própria dos autores, a partir dos dados do portal do estudante do IFPB cursos de graduação (2015).

Desses dados, é possível inferir que, dos 10 campi que atualmente ofertam cursos de graduação no IFPB com um total geral de 38 cursos, os campi de João Pessoa, Sousa e Campina Grande concentram a oferta de 27 cursos, o que representa um percentual geral de $71,1 \%$ de todos os cursos de graduação oferecidos no IFPB. A situação de cada um desses campi será analisada individualmente nos itens seguintes.

\subsection{O IFPB campus João Pessoa}

O IFPB campus João Pessoa (JP) é o mais antigo do instituto, um campus centenário que foi instituído em 1909 como uma das 19 Escolas de Aprendizes Artífices criadas pelo governo federal (BRASIL, 1909), ofertando atualmente cursos nos níveis médio e superior. Está localizado na cidade de João Pessoa, capital da Paraíba, considerada a 24a maior cidade do país com uma população estimada entre os anos de 2010 e 2019 respectivamente em 723.515 e 809.015 habitantes (IBGE, 2019), possuindo um IDH de 0,763. O setor de serviços domina a atividade econômica, sendo responsável por mais de $61 \%$ da geração de emprego e renda da cidade, e tem na administração pública e na educação um de seus maiores contingentes de trabalhadores. Além do setor de serviços, os principais ramos de atividade econômica do município são o industrial, com $17 \%$ da geração de emprego e renda, e o comércio de mercadoria, com 19\%, conforme dados do IFPB (PPC, 2016). 
Diante desse panorama, o IFPB campus João Pessoa assume espaço de referência em educação profissional e tecnológica, em nível de graduação, oferecendo cursos nas modalidades de tecnólogos, bacharelados, licenciaturas (PDI do IFPB - 2015). Em 2015, o campus ofertou 14 tipos de cursos superiores distribuídos em 12 cursos presenciais e 2 na modalidade a distância (EaD) (PDI2015), demonstrando a prevalência pela oferta de cursos presenciais até o ano de 2015, conforme pode ser visto no Quadro 1.

Quadro 1 - Cursos superiores de graduação do IFPB campus João Pessoa (2015)

\begin{tabular}{|l|c|c|}
\hline \multicolumn{1}{|c|}{ Curso } & Tipo de Curso & Modalidade \\
\hline Automação Industrial & Tecnólogo (Matutino) & Presencial \\
\hline Construção de Edifícios & Tecnólogo (Noturno) & Presencial \\
\hline Design de Interiores & Tecnólogo (Matutino) & Presencial \\
\hline Geoprocessamento & Tecnólogo (Matutino) & Presencial \\
\hline Gestão Ambiental & Tecnólogo (Matutino) & Presencial \\
\hline Negócios Imobiliários & Tecnólogo (Noturno) & Presencial \\
\hline Sistemas de Telecomunicações & Tecnólogo (Noturno) & Presencial \\
\hline Sistemas para Internet & Tecnólogo (Vespertino) & Presencial \\
\hline Redes de Computadores & Tecnólogo (Vespertino) & Presencial \\
\hline Administração Pública & Bacharelado & EaD \\
\hline $\begin{array}{l}\text { Administração 2 turmas - diurno e uma } \\
\text { turma noturno }\end{array}$ & Bacharelado (Integral) & Presencial \\
\hline Engenharia Elétrica & Bacharelado (Integral) & Presencial \\
\hline Letras - Língua Portuguesa & Licenciatura (Integral) & EaD - Polos \\
\hline Química & Licenciatura (Vespertino) & Presencial \\
\hline
\end{tabular}

Fonte: Elaboração própria dos autores com base em dados do site oficial do IFPB Campus João Pessoa - GraduaçãoEducação Superior, ano 2018. Portal do Estudante- https://estudante.ifpb.edu.br/cursos/146.

A Educação Superior - cursos de graduação - começou a ser ofertada, no campus João Pessoa, no ano de 1999, quando a instituição foi transformada de Escola Técnica em CEFET, tendo a sua expansão se efetivado mais fortemente entre os anos 2008 e 2016, com uma progressão média da oferta de dois cursos por ano, ou a cada dois anos, como mostra os dados do Gráfico 2. 


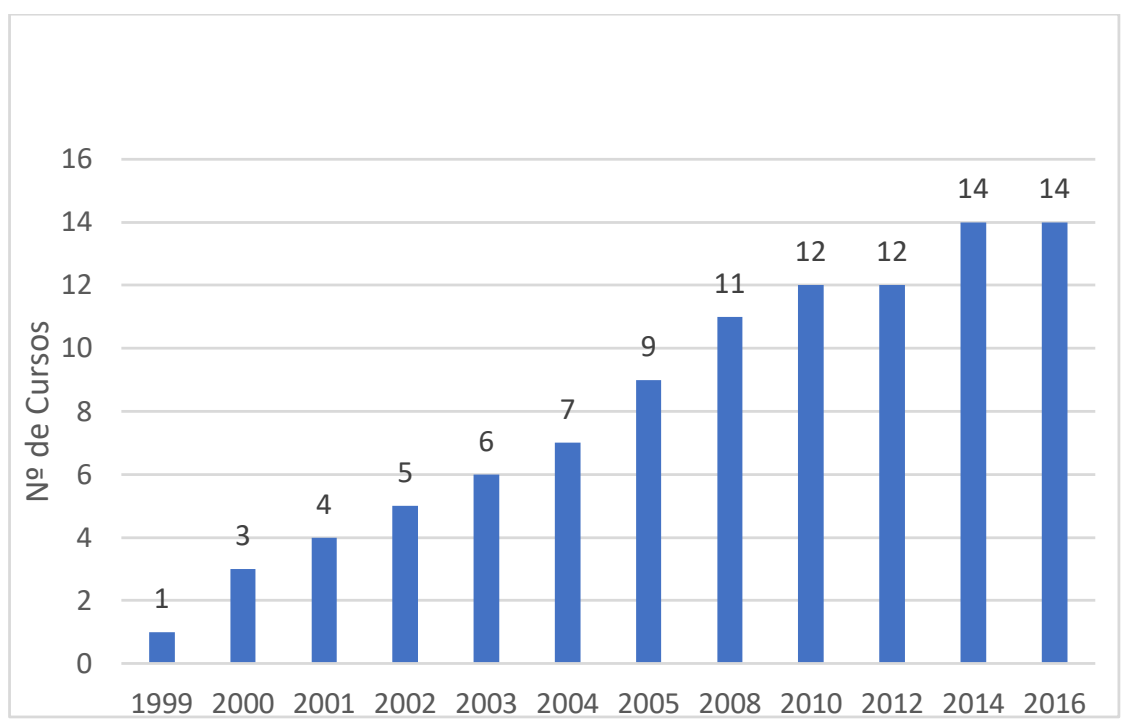

Gráfico 2 - Progressão de oferta de cursos de graduação no IFPB campus João Pessoa de 1999 a 2016

Fonte: Elaboração própria dos autores, a partir de Dados do Controle Acadêmico do Campus JP, 1999, 2001, 2002, 2003, 2004, 2005, 2008, 2010, 2012, 2014, 2016.

Destaca-se que a expansão da oferta de cursos de graduação no campus João Pessoa apresenta uma progressão de crescimento até o ano de 2014, com uma estabilização nos anos de 2010, 2012, 2014 e 2016. Além disso, os dados de progressão da expansão dos cursos de graduação apresentam como tendência atender, em grande parte, às características dos Arranjos Produtivos Locais, a exemplo dos cursos de bacharelados na área de Administração, automação industrial e dos cursos na área de informática.

O alcance das metas quantitativas relativo aos números definidos para a expansão nos PDIs de 2005 a 2015 do IFPB e nas políticas do governo federal para os IFs, de expansão dos campi e dos cursos de graduação, no período de análise desta pesquisa, foi obtido em sua plenitude e até mesmo em números de maior abrangência para algumas das metas (ARAÚJO, 2019).

\subsubsection{Parcerias público-privadas e convênios: configuração no Campus João Pessoa}

No campus João Pessoa, as parcerias entre instituições públicas encontram-se nos registros de convênios com universidades federais - a exemplo da Universidade Federal do Rio Grande do Norte (UFRN) e da Universidade Federal da Paraíba (UFPB), ambas oportunizando qualificação dos servidores (docentes e técnicos) seja de um campus específico e/ou de todos os servidores do IFPB (por meio da definição de cotas específicas, respectivamente, para Doutorado e Mestrado), além dos projetos que envolvem os cursos de graduação e seus estudantes por meio de seminários e encontros científicos.

No concernente ao setor privado, ocorre parcerias com empresas, a exemplo da Cisco, Sony, mais especificamente nos cursos de informática. As associações/parcerias com o setor privado têm resultado em aproximação da formação dos estudantes com o perfil de demandas requeridas pelas 
empresas parceiras e são fundamentadas nas características das necessidades do mercado de trabalho, oportunizando, ainda, quando possível, a aquisição de estrutura física e de equipamentos para o campus em alguns desses projetos.

Como resultado da coparticipação em parcerias, o IFPB passou a compor o seleto grupo de IFs contemplados pelo governo federal com um polo de inovação, localizado no campus João Pessoa desde 2015, contando com um prédio construído com recursos advindos da parceria com projetos de inovação mediados na gestão de 2014 aos dias atuais, tendo como um dos objetivos diminuir lacunas que existiam na formação dos cursos superiores do IFPB em face às demandas do mercado de trabalho, a partir do contexto real definido pelas empresas parceiras.

Demarca-se, ademais, que o IFPB procura articular os cursos de graduação - envolvendo professores, alunos, pesquisadores, comunidade e empresas - a projetos de inovação atualmente dirigidos mais diretamente aos cursos de informática e engenharia elétrica.

Embora o IFPB seja uma instituição pública, dependente de recursos da União, tem efetivado, ainda que de forma insipiente, parcerias com o setor privado em sintonia com as políticas nacionais de CT\&I, estabelecida nas diretrizes da Estratégia Nacional de Ciência, Tecnologia e Inovação 2016/2022 (BRASIL, 2016). Essas parcerias com as empresas têm aproximado, de forma crescente, a instituição ao setor privado, ampliando portanto, as possibilidades da introdução da lógica mercantil na educação pública.

Tal possibilidade assume diferentes contradições que vão desde a relação de abertura para a necessidade de captação de recursos advindos do setor privado em detrimento do público, como entre os próprios interesses de ambos os lados: as instituições públicas e as empresas. Como explicam Salomon e Silva (2007, p. 14): “[...] as universidades priorizam a publicação de suas pesquisas ao contrário das empresas que enfatizam a importância das patentes para evitar que os resultados de suas descobertas sejam acessados facilmente".

Embora os elementos do mercado - tais como metas, produtividade e busca do lucro estejam fortemente atrelados aos resultados das pesquisas desenvolvidas pelos polos de inovação, considera-se que as parcerias trazem consigo elementos importantes de desenvolvimento para a formação dos estudantes, reunindo os estudos teóricos pensados para a aplicação real das demandas do mundo do trabalho.

Em linhas gerais, a expansão da Educação Superior - cursos de graduação no campus do IFPB de João Pessoa - seguiu um processo de expansão significativa em sua oferta de cursos, passando de 1 curso, em 1999, para 14 cursos, em 2015, cursos esses que mantêm uma relação com os setores de serviços, industrial e de educação, caracterizando uma estreita relação com os arranjos produtivos locais.

O destaque para a materialização em relação às parcerias entre empresas públicas e privadas, assim como a efetivação do polo de inovação com maior destaque para os cursos do campus de João Pessoa, são demonstrativos de uma maior maturidade de tempo de desenvolvimento institucional de Educação Superior deste campus, atreladas ao significativo número de cursos, de docentes e, portanto, de experiências com a oferta de Educação Superior. 


\subsection{O IFPB campus Sousa}

O IFPB campus Sousa apresenta um histórico identitário diferente dos outros campi do instituto - oriundos quase que em sua totalidade do meio urbano e do CEFET. O campus Sousa é proveniente da antiga Escola de Economia Doméstica Rural de Sousa, criada em 1946 pela portaria de $n^{\circ} 552$, de 04 de julho de 1946, assim como pela lei orgânica do ensino agrícola que definia os tipos de estabelecimentos do ensino agrícola, como as escolas de iniciação agrícola, as escolas agrícolas e as escolas agrotécnicas, estabelecendo suas bases de organização, consistindo, em princípio, em um ensino de primeiro e segundo graus, com o objetivo de preparar os trabalhadores (operários, mestres e técnicos) para a agricultura (Decreto-lei no 9.613, de 20 de agosto de 1946).

A Escola Agrotécnica de Sousa foi integrada ao IFPB (Decreto no 6.095/2007), passando a ser Instituto Federal de Educação, Ciência e Tecnologia da Paraíba, campus Sousa (BRASIL, 2008). As características do instituto dizem muito de sua localização no município de Sousa-PB, incluído na área geográfica de abrangência do semiárido brasileiro, definido pelo Ministério da Integração Nacional em 2005.

É na agricultura irrigada e na ovinocaprinocultura que a economia da cidade e da região se baseia, e é nesse contexto que o município de Sousa tem se destacado como grande produtor de coco e uma das áreas de maior potencial de desenvolvimento da irrigação e do complexo agroindustrial processador de frutas, hortaliças, matéria-prima para a indústria, tanto para o abastecimento interno quanto para a exportação. É hoje uma cidade de porte médio, com uma população estimada entre os anos de 2010 e 2019 respectivamente em 65.803 e 69.444 habitantes (IBGE, 2019). Possui no seu território dois perímetros irrigados: o de São Gonçalo (DNOCS) e o Orgânico Várzeas de Sousa (Governo do Estado). A economia da cidade é bastante diversificada, embora tenha no setor de serviços o maior responsável pela arrecadação de impostos no município.

No ramo industrial, Sousa se destaca como uma das cidades mais industrializadas da Paraíba, com pouco mais de 164 indústrias, dentre as quais se destacam empresas de laticínios - Isis Laticínio, Belo Vale (empresa de sorvete), Flor de Liz, além de uma indústria de concreto e outra de vassouras.

$\mathrm{Na}$ Educação Superior, atualmente o município conta com 02 instituições públicas: o Instituto Federal de Educação, Ciência e Tecnologia da Paraíba (IFPB - campus Sousa) e a Universidade Federal de Campina Grande (UFCG - campus Sousa) (IFPB-PPC, 2016). É o segundo campus mais antigo do IFPB e o segundo maior em oferta de Educação Superior, ofertando 07 cursos de graduação estruturados em três unidades. A unidade sede, localizada na área urbana da cidade de Sousa, onde funciona a parte administrativa e financeira da instituição, bem como os cursos da área de informática no horário diurno e o curso superior de Licenciatura em Química no horário noturno.

$\mathrm{Na}$ área urbana de Sousa, o campus conta ainda com a unidade do Centro Vocacional Tecnológico (CVT) Salomão Benevides Gadelha, fundado em 2011, definido, em princípio, como uma unidade de ensino e de profissionalização voltada para a difusão do acesso ao conhecimento científico e tecnológico, de conhecimentos práticos na área de serviços técnicos e de transferência 
de conhecimentos tecnológicos no seu âmbito de atuação. Atualmente, no CVT funcionam os polos dos cursos superiores na modalidade a distância.

Na unidade São Gonçalo, localizada na zona rural a 17 km da cidade de Sousa, também conhecida como escola-fazenda, é o local onde funcionam os demais cursos - técnicos e superiores. A instituição conta com uma grande extensão em área territorial, laboratórios, espaços de produção e criação de animais (ARNAUD, 2018).

Atualmente, o campus Sousa oferece cursos técnicos e superiores de Agropecuária, Agroindústria, Informática e Meio Ambiente. Compondo a estrutura do campus rural - unidade São Gonçalo, com perfil na área de agropecuária, aspecto que se destaca com perfil bem diferente dos outros campi do IFPB, conta com a criação e manutenção de animais para aulas práticas e pesquisas, além de um hospital veterinário inaugurado no ano de 2014, e uma estrutura de alojamentos para acolher os estudantes oriundos de outras cidades (ARNAUD, 2018). Os cursos de Agroecologia da unidade de São Gonçalo contam com toda uma nova estrutura física que comporta salas de aulas, salas de professores, laboratórios, banheiros, copa e outros espaços.

\subsubsection{A oferta e a expansão dos cursos de graduação no IFPB campus Sousa}

Em nível de graduação, o campus oferta sete cursos nas três modalidades: cursos de tecnólogos, licenciaturas e de bacharelado, os quais se destacam como oferta exclusiva, em todo o IFPB, os cursos de Agropecuária, Medicina Veterinária e Alimentos.

A oferta e a expansão da Educação Superior - cursos de graduação no campus Sousa podem ser observadas no Gráfico 3.

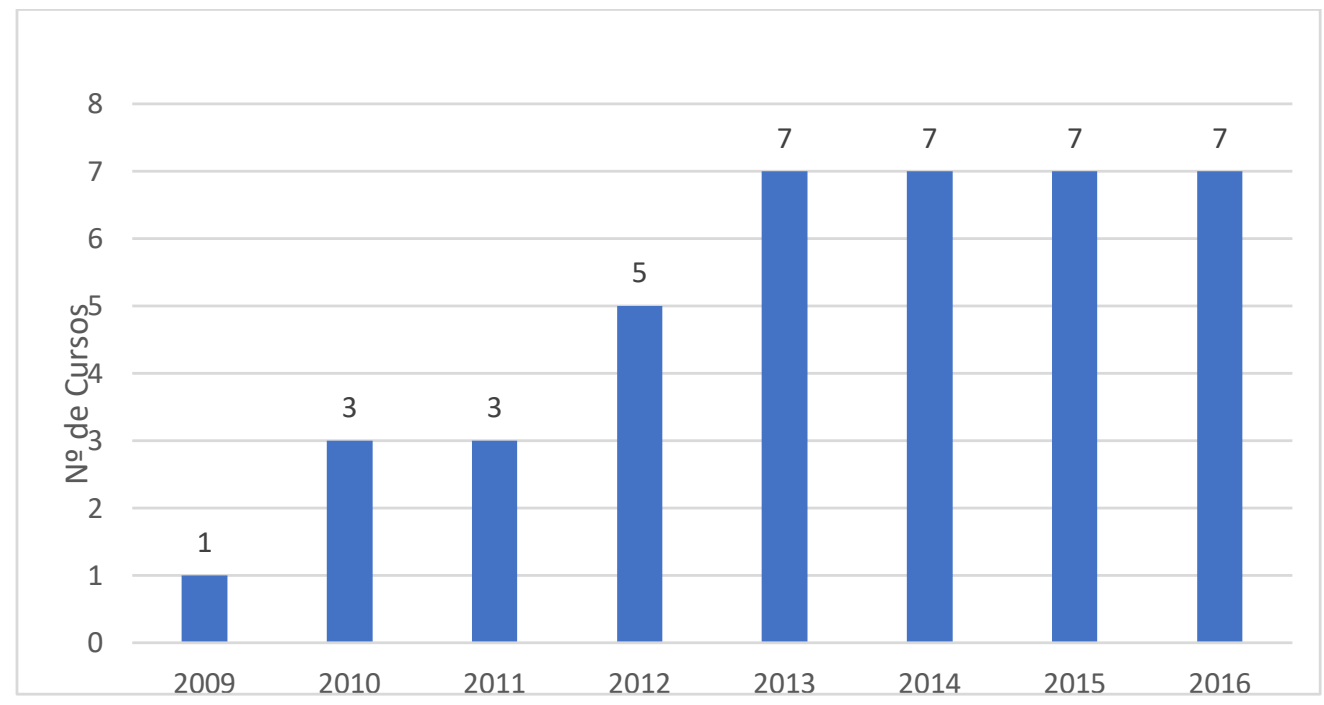

Gráfico 3 - Oferta e expansão dos cursos de graduação do campus Sousa de 2009 a 2016

Fonte: Elaboração própria dos autores com base em dados do Controle Acadêmico do Campus Sousa, anos 2009, 2010, 2011, 2012, 2013, 2014, 2015, 2016. 
Os cursos superiores de graduação do campus Sousa, como mostram os dados do Gráfico 3, seguem uma progressão mais demorada e uniforme se comparada à progressão de oferta dos cursos do campus de João Pessoa. Inicia em 2009 com a oferta de, apenas, um curso, sendo ampliada, em 2010, para 3 e, em 2013, para 7 cursos, quando estabiliza a sua expansão até 2016.

Os cursos, em sua maioria, são ofertados na modalidade presencial, sendo seis - dos sete cursos de graduação - nessa modalidade e, apenas, um na modalidade a distância, conforme descrito no Quadro 2.

Quadro 2 - Cursos superiores ofertados pelo IFPB campus Sousa

\begin{tabular}{|l|l|l|}
\hline \multicolumn{1}{|c|}{ Tipo de Curso /ano de criação } & Modalidade & \multicolumn{1}{c|}{ Local } \\
\hline Curso de Tecnologia em Agroecologia - 2009 & Presencial & Unidade São Gonçalo - zona rural \\
\hline Tecnologia em Alimentos - 2010 & Presencial & Unidade São Gonçalo - zona rural \\
\hline Bacharelado em Medicina Veterinária - 2012 & Presencial & Unidade São Gonçalo - zona rural \\
\hline $\begin{array}{l}\text { Licenciatura em Química - 2010 } \\
\text { Licenciatura em Letras- Língua Portuguesa - }\end{array}$ & Presencial & Campus Central - urbano \\
\hline Licenciatura em Educação Física - 2013 & Presencial & $\begin{array}{l}\text { Unidade São Gonçalo - zona rural } \\
\text { (CVT) }\end{array}$ \\
\hline Licenciatura em Educação Física - 2013.2 & Presencial & Unidade São Gonçalo \\
\hline
\end{tabular}

Fonte: Elaboração própria dos autores, a partir de dados do Controle Acadêmico do Campus Sousa e site oficial do IFPB, Campus Sousa, cursos de Graduação, 2018.

Com base nesses dados, consta-se que o primeiro curso de graduação ofertado no campus Sousa foi o de Tecnólogo em Agroecologia, criado no ano de 2009. Os cursos de licenciatura representam a maior oferta do campus até 2015/2016, contando com três cursos de licenciatura dos 7 cursos de graduação ofertados, contrariando assim a própria lógica do IFPB e dos IFs em nível nacional, de predominância para a oferta dos cursos de tecnólogos, fato que em parte atende a prioridade definida na lei de criação dos IFs para os $20 \%$ das vagas anuais para os cursos de licenciatura (BRASIL, 2008).

Até o ano de 2015, a oferta de cursos de graduação do campus acompanhou a ordem anual de oferta e expansão exposta na Quadro 3.

Quadro 3 - Progressão da oferta e expansão dos cursos de graduação do IFPB campus Sousa

\begin{tabular}{|l|l|l|}
\hline Ano & $\begin{array}{l}\text { No de } \\
\text { cursos }\end{array}$ & Tipos de Curso \\
\hline 2009 & 01 & Agroecologia. \\
\hline
\end{tabular}




\begin{tabular}{|c|c|c|}
\hline 2010 & 03 & Agroecologia, Alimentos, Licenciatura em Química. \\
\hline 2012 & 05 & $\begin{array}{l}\text { Agroecologia, Alimentos, Licenciatura em Química, Veterinária, } \\
\text { Licenciatura em Letras EaD. }\end{array}$ \\
\hline 2013 & 07 & $\begin{array}{l}\text { Agroecologia, Alimentos, Licenciatura em Química, Veterinária, } \\
\text { Licenciatura em Letras EaD, Licenciatura em Educação Física/Educação } \\
\text { Física pelo Parfor; }\end{array}$ \\
\hline 2014 & 07 & $\begin{array}{l}\text { Agroecologia, Alimentos, Licenciatura em Química, Veterinária, } \\
\text { Licenciatura em Letras EaD, Licenciatura em Educação Física/Educação } \\
\text { Física pelo Parfor. }\end{array}$ \\
\hline 2015 & 07 & $\begin{array}{l}\text { Agroecologia, Alimentos, Licenciatura em Química, Veterinária, } \\
\text { Licenciatura em Letras EaD, Licenciatura em Educação Física/Educação } \\
\text { Física pelo Parfor. }\end{array}$ \\
\hline
\end{tabular}

Fonte: Elaboração própria dos autores, a partir dos dados do Controle Acadêmico do Campus, 2009, 2010, 2012, 2013, 2014 e 2015.

Observa-se que a oferta de cursos tecnológicos pelo IFPB campus Sousa registra traços diretamente associados aos arranjos produtivos locais e regionais, caracterizando ainda mais a importância do campus na região e sua atuação em relação ao atendimento ao que prescreve o artigo 6ㅇ, I - da sua lei de criação, Lei de $n$ ㅇ 11.892, de 29 de dezembro de 2008, ao priorizar a oferta de cursos técnicos e superiores, oferecendo educação profissional e tecnológica em todos os seus níveis e modalidades, formando e qualificando cidadãos com vistas a atuação profissional nos diversos setores da economia, com ênfase no desenvolvimento socioeconômico local, regional e nacional (BRASIL, 2008).

As características gerais da expansão da Educação Superior no campus Sousa - cursos de graduação - seguiram uma progressão de oferta contínua entre um e dois cursos por ano, de 2009 a 2013, mantendo uma estabilização dos 07 cursos de 2013 a 2016. Outro favor resultante da caracterização da expansão dos cursos foi a observação para o ineditismo de oferta exclusiva pelo IFPB campus Sousa dos cursos superiores de tecnologia em Agropecuária, bacharelado em Medicina Veterinária e tecnologia em Alimento. Esses cursos, pelas suas características, registram a necessidade de maior percentual de recursos para a sua manutenção porque envolvem a manutenção de animais e as especificidades do hospital veterinário. 


\subsubsection{Parceria público-privada: recortes do campus Sousa}

As parcerias e convênios firmados pelo campus Sousa, até o ano de 2018, têm sido registrados mais diretamente para oportunizar visitas técnicas, trocas de experiências e estágios para os alunos, a exemplo do registro de uma parceria com a empresa ISIS - de lacticínios - com alunos do curso de alimentos. Essas cooperações ainda são em número pequeno, resultando na necessidade de ampliar essa articulação do campus com possíveis parceiros para os cursos de Educação Superior e suas pesquisas integradas.

Sobre as possibilidades de firmar parcerias entre o campus e instituições públicas e privadas, pode-se inferir que o campus tem um significativo potencial de docentes e alunos, fator que aumenta as condições para buscar maior abertura para novos projetos, de forma a ampliar essas relações em prol da formação dos estudantes e da otimização da pesquisa tecnológica no campus.

\subsection{O IFPB campus Campina Grande}

O campus Campina Grande, localiza-se na cidade de mesmo nome, caracterizada como o maior e mais populoso município do interior da Paraíba, com uma população estimada no período entre 2010 e 2019, respectivamente com 385.213 e 409.731 habitantes (IBGE, 2019), sendo considerado um dos principais polos industriais e tecnológicos da região Nordeste. De acordo com dados da Fundação Parque Tecnológico da Paraíba (PaqTcPB, 2014), Campina Grande vem sendo considerada, nos últimos anos, um polo internacional de tecnologia, um celeiro de profissionais de tecnologia, fato que atrai investimentos de multinacionais em projetos de pesquisa nas instituições de ensino, a exemplo das multinacionais como a Sony, HP (Hewlett-Packard) e AOC (Admiral Overseas Corporation), assim como de recrutamento de vagas de trabalho para os profissionais formados (ARAÚJO, 2019).

O campus do IFPB de Campina Grande foi inaugurado no ano de 2007, ainda como Unidade de Ensino Descentralizada do Centro Federal de Educação Tecnológica da Paraíba, e transformado em campus do IFPB a partir da edição da Lei no 11.892/2008 (BRASIL, 2008), ofertando cursos de graduação desde 2007, como mostra o Gráfico 4. 


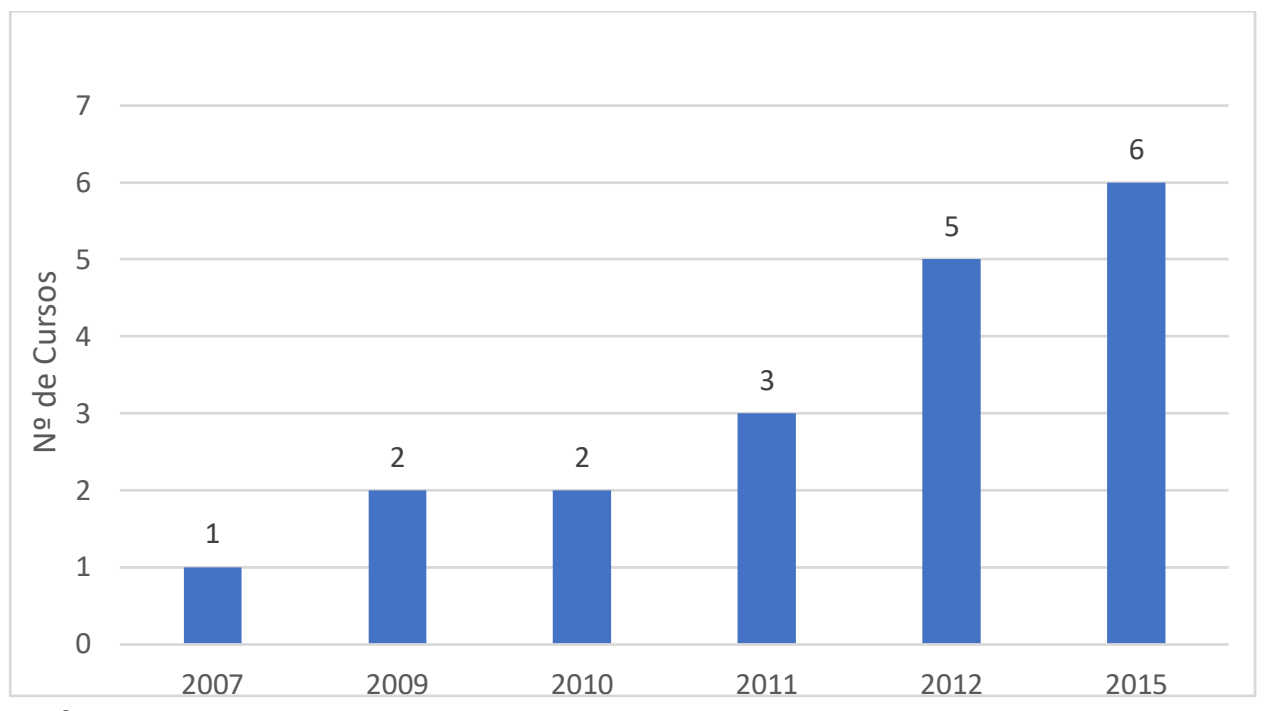

Gráfico 4 - Oferta e expansão dos cursos de graduação do campus de Campina Grande (20072015)

Fonte: Elaboração própria dos autores com base em dados do Controle Acadêmico do campus Campina Grande, anos 2007, 2009, 2010, 2011, 2012, 2015.

Dos 6 cursos superiores de graduação ofertados pelo Campus Campina Grande, 5 são presenciais e 1 a distância (EaD), o que reforça as características da oferta dos cursos presenciais no IFPB até o ano de 2015, contemplando as três modalidades de cursos com 3 licenciaturas, 2 tecnólogos e 1 bacharelado, distribuídos conforme ilustrado no Quadro 4.

Quadro 4- Cursos superiores do IFPB campus Campina Grande

\begin{tabular}{|l|l|l|}
\hline \multicolumn{1}{|c|}{ Curso } & \multicolumn{1}{c|}{ Tipo de Curso } & \multicolumn{1}{c|}{ Modalidade } \\
\hline Telemática & Tecnólogo - Integral & Presencial \\
\hline Construção de Edifícios & Tecnólogo - Integral & Presencial \\
\hline Engenharia da Computação & Bacharelado - Integral & Presencial \\
\hline Letras - Língua Portuguesa & Licenciatura - Integral & EaD \\
\hline Física & Licenciatura - Integral & Presencial \\
\hline Matemática & Licenciatura - Noturno & Presencial \\
\hline
\end{tabular}

Fonte: Elaboração própria dos autores, a partir dos dados do site oficial do IFPB campus Campina Grande-Graduação, Portal do estudante, 2018.

Desses seis cursos superiores de graduação oferecidos pelo campus Campina Grande, o primeiro foi o de tecnólogo em Telemática. Outro ponto de destaque tem sido a consonância dos cursos de graduação com os arranjos produtivos locais e nacionais, a exemplo dos cursos de Telemática e Engenharia da Computação que são cursos que atendem às necessidades de formação de profissionais nessa área, acolhendo diretamente às demandas de formação requeridas como destaque no município de Campina Grande, além de possibilitar, em muitos dos casos, que alunos dos cursos técnicos sigam a formação superior na área da informática (verticalização). 
Os cursos de licenciatura formam professores para a educação básica nas áreas, sobretudo, de matemática e física para atender às demandas regionais e nacionais, acolhendo as necessidades advindas da sociedade, assim como seguindo os critérios de prioridade de oferta para as licenciaturas nos institutos federais, como descrito no Art. 7 b do texto da lei de criação dos IFs, Lei no 11.892/2008 (BRASIL,2008).

O perfil de expansão da oferta dos cursos de graduação do campus Campina Grande apresenta uma tendência de adaptação que atende às demandas de desenvolvimento local, tanto para as licenciaturas, como descrito anteriormente, como na definição dos cursos de Engenharia e tecnólogo na área de informática - Engenharia da Computação, por sua relação direta com o perfil de desenvolvimento do polo industrial do município, proporcionando, dessa forma, um maior equilíbrio entre o acesso à formação e ao mundo do trabalho.

\subsubsection{Parcerias público-privadas e convênios: Campus Campina Grande}

O campus de Campina Grande, por estar localizado dentro de um importante parque industrial em desenvolvimento na Paraíba - considerado um dos principais polos industriais da região nordeste e o principal polo tecnológico da América Latina, segundo a revista americana Newsweek $(2001)^{3}-$, concentra indústrias na área de tecnologia e informática, aspecto que dá contorno para a definição dos cursos de graduação oferecidos pelo IFPB, assim como abre oportunidades para parcerias e convênios. Nos registros identificados no campus, tem-se para o curso de Engenharia da Computação o desenvolvimento de projetos em parceria com empresas privadas, a exemplo do Instituto Venturus e do Virtus - da UFCG, Foxconn, os quais agregam aporte financeiro, experiências profissionais para os alunos do campus do IFPB, que unem conhecimento teórico e prático objetivados para atender a demandas reais advindas das empresas, além do ganho para a instituição, na aquisição em infraestrutura física que contempla sala de reuniões, sala de professores, dater center, um laboratório de capacitação com 30 computadores e um laboratório de prototipagem com diversos equipamentos, tendo como proposta de retorno o dever de ministrar cursos na área de microeletrônica para discentes do campus.

Outra parceria público-privada foi com a Huawei, empresa que fabrica produto para a rede de computadores, sociedade que incluiu projetos de capacitação para estudantes dos cursos. Além desses, outros projetos foram firmados, a exemplo da ASUS e de parcerias com instituições públicas, principalmente estes últimos para estágios de alunos na área de informática.

De modo sintético em relação à expansão da Educação Superior - cursos de graduação no campus do IFPB de Campina Grande, é possível destacar que apresenta características importantes de desenvolvimento, embora seja um campus relativamente novo, com apenas oito anos de funcionamento, e tenha muitos desafios a serem enfrentados. É um campus que se sobressai

\footnotetext{
${ }^{3}$ Disponível em: http://www.dignow.org/area/reportagens-do-passado-campina-grande-destaque-na-revista-newsweekem-2001-884678-27906. Acesso em: 10 jan. 2019.
} 
atualmente, entre os campi do IFPB, em termos de condições de estrutura física e de pessoal para comportar a expansão da Educação Superior, além de se destacar em relação aos ganhos advindos das parcerias de projetos com empresas privadas, relacionadas aos cursos de Engenharia da Computação, demonstrando uma tendência de oferta para os cursos de licenciaturas em LetrasLíngua Inglesa, Física e Matemática, os quais corresponderam a 50\% de sua oferta na graduação.

\section{CONSIDERAÇÕES FINAIS}

As análises desenvolvidas neste artigo, permite explicitar que o movimento de expansão do IFPB, em termos de ampliação no número de campi, como uma meta estabelecida nos três PDIs de 2005, 2010 e 2015 - foi alcançada com sucesso em relação ao período de 2008 a 2015. Nesse recorte de tempo, o quantitativo de novos campi passou de 3 para 21, correspondendo a $600 \%$ de crescimento. A criação desses campi oportunizou a interiorização do IFPB em todo o estado da Paraíba, consolidando, dessa forma, as metas de interiorização e de expansão da rede de educação profissional e tecnológica traçadas pelo governo federal e pelo IFPB na Paraíba.

A expansão da Educação Superior - cursos de graduação presencial - também é considerada uma meta consolidada, uma vez que ela ocorreu de forma paralela à criação de cada campus, sendo oferecida, de forma gradativa, em cada um dos campi pesquisados. A análise do crescimento, a partir dos dados registrados correspondentes a cada campus para o período de 2008 a 2015, seguiu uma progressão de crescimento em todos eles, porém, elementos diferenciados se destacaram, quando temos para o campus de João Pessoa, uma taxa de crescimento de, apenas, 27, 27\%, considerando que passou, no período em análise, de 11 para 14 cursos, enquanto que para os novos campi Sousa e Campina Grande, esse crescimento foi, respectivamente, na ordem de 1 para 7 (600\%) e 1 para 6 cursos (500\%). Esse expressivo aumento no número de cursos de graduação, notadamente nos campi do interior, demonstra o quanto a política de expansão da Educação Superior ocorreu de forma intensa no IFPB, consolidando o processo de interiorização previsto em seus PDIs.

O destaque para o crescimento dos cursos nos campi do interior (interiorização), como fator diferenciador da expansão da Educação Superior no IFPB, apresenta-se como importante dimensão social, uma vez que foi e é oportunizador do acesso à Educação Superior pública aos jovens do interior em sua cidade e/ou em uma cidade vizinha a seu município, muitos dos quais por questões econômicas não teriam condições de virem morar em uma capital, quando se observava a centralização dessas instituições.

Os tipos de cursos de graduação seguiram em sua grande maioria a oferta atrelada aos arranjos produtivos locais, porém, quando analisados em relação de comparação e repetição entre eles, observa-se que os campi de João Pessoa e Campina Grande seguem um perfil de maior similaridade e repetição entre os cursos e que o campus de Sousa se diferencia pelo ineditismo, 
advindo de seu perfil agrícola, enquanto Escola Agrotécnica, instituição com perfil diferenciado do antigo CEFET, com destaque para a exclusividade em relação à oferta dos cursos de Agropecuária, Medicina Veterinária e Alimentos, o que demonstra que as diferenças entre as instituições integradas para compor o IFPB se realçam em suas formas específicas e registradas no recorte de tempo desta pesquisa.

Outro destaque foi para a maior oferta dos cursos de graduação na modalidade presencial, assim como pela oferta na modalidade de tecnólogo como um ponto unificador entre os cursos. A prevalência da oferta dos cursos de tecnólogos no IFPB reafirma a tendência da Educação Superior para o modelo americano de universidade (KERR, 1982), articulado à proximidade de adaptação do perfil dessa instituição aos padrões ditados pelo neoliberalismo, quanto à flexibilização para a oferta de cursos com duração de médio e curto prazo. A reforma do estado brasileiro, iniciada em 1995 em relação às políticas para a Educação Superior, vem definindo a abertura para um "novo" e diversificado perfil institucional de Educação Superior, com maior grau de variação em sua forma e em seus tipos - modernos, flexíveis e dinâmicos - para atender tanto às demandas sociais quanto às demandas do mercado por maior formação e qualificação.

As experiências do IFPB, com destaque para o aumento das parcerias e convênios com instituições públicas e/ou privadas, reafirmam uma tendência que vem ampliando os espaços para a captação de recursos advindos de empresas privadas mediando o processo de formação dos alunos da graduação e da pesquisa, uma vez que, por meio dos convênios firmados em parcerias que englobam a construção do conhecimento desenvolvido no IFPB, também são considerados os interesses das empresas parceiras. As parcerias de convênios apresentaram experiências específicas por campi, a exemplo do campus de campus João Pessoa que ampliou suas parcerias com a UFPB em relação a atividades e eventos das licenciaturas.

Os destaques para a ampliação do alcance de captação dos recursos oriundos de empresas privadas foram para os campi de João Pessoa e Campina Grande. O campus João Pessoa sedia o Centro de Inovação do IFPB que, por seu desenvolvimento sistêmico, abarca todos os campi, porém, em relação aos campi do interior, ainda o faça de forma incipiente. O campus de Campina Grande, como um dos mais recentes a ofertar Educação Superior, revela tendência de crescimento para novas parcerias, fator que se aporta por sua localização em região considerada polo de desenvolvimento de tecnologia.

O campus de Sousa, em relação às parcerias e convênios com instituições privadas, encontrase, ainda, em um formato muito embrionário e/ou mesmo ainda não experimentaram esse modelo. É perceptível que o IFPB é uma instituição que assume em seu perfil um importante papel a desenvolver na área da ciência, tecnologia e inovação, unindo teoria e prática na pesquisa aplicada e em sua aproximação com o mundo do trabalho, porém tem, desde 2014 , dado sinais cada vez mais acentuados de disponibilidade de retração em seus recursos públicos advindos do governo 
federal, fator que certamente implicará a busca pela ampliação das parcerias com empresas privadas.

O movimento de expansão dos cursos de graduação do IFPB segue a lógica do novo padrão de modernização para a Educação Superior incluso no novo paradigma de produção capitalista neoliberal, cujas características de um estado mínimo adentram a dinâmica de organização e atuação desta instituição, incentivando as parcerias com empresas privadas. Contudo, elementos de alcance social também permeiam o seu novo perfil enquanto IFPB, pois a instituição, de forma contraditória, permitiu uma ampliação histórica da oferta e da interiorização de cursos de Educação Superior em todo o estado da Paraíba, com destaque para a sua maior oferta pela modalidade presencial e de cursos de tecnólogos.

\section{REFERÊNCIAS}

ARAÚJO, M.S. V. de. (2019). Um estudo da expansão da educação superior no IFPB: desafios institucionais e alcance social. Tese de doutorado (Centro de Educação - Programa de PósGraduação em Educação) Universidade Federal do Rio Grande do Norte, Natal.

ARNAUD, A. P. de A. R. (2018). Um processo identitário docente e seu desdobramento no ensinoaprendizagem de história no IFPB de Sousa. Dissertação (Mestrado em Programa de PósGraduação em Ensino) - Universidade do Estado do Rio Grande do Norte - Campus Pão dos Ferros.

BENTIN, P. (2017). O Ensino de Graduação nos Institutos Federais. In: ANOS, Malyta Brandão dos; RÔSAS, Gisele. As políticas públicas e o papel social dos Institutos Federais de Educação, Ciência e Tecnologia. Natal: IFRN.

BRASIL. (1909). Decreto no. 7.566 de 23 de setembro de 1909. Cria nas Capitais dos Estados da República Escolas de Aprendizes Artífices para o ensino profissional primário e gratuito. Coleções de Leis do Brasil. Imprensa Nacional: Rio de Janeiro, 31 dez. 1909. Disponível em: http://portal.mec.gov.br/setec/arquivos/pdf3/decreto_7566_1909.pdf. Acesso em: 10 jan. 2018.

BRASIL. (2016). Estratégia Nacional de Ciência, Tecnologia e Inovação 2016|2022: Ciência, Tecnologia e Inovação para o Desenvolvimento Econômico e Social. Ministério da Ciência, Tecnologia, Inovações e Comunicações (MCTIC), Brasília, DF. 2016. Disponível em: http://www.finep.gov.br/images/a-

finep/Politica/16_03_2018_Estrategia_Nacional_de_Ciencia_Tecnologia_e_Inovacao_2016_2022.pdf. Acesso em: 03 fev. 2019.

BRASIL. (2008). Lei 11.892, de 29 de dezembro de 2008. Institui a Rede Federal de Educação Profissional, Científica e Tecnológica, e dá outras providências. Diário Oficial da União de 30/12/2008. Brasília. 
BRASIL. (2014). Plano Nacional de Educação (PNE) 2014-2024: Lei no 13.005, de 25 de junho de 2014, que aprova o Plano Nacional de Educação (PNE) e dá outras providências. Brasília: Câmara dos Deputados, Edições Câmara.

IBGE. (2019). INSTITUTO BRASILEIRO DE GEOGRAFIA E ESTATISTICA. Censo Demográfico: Diretoria de Pesquisas - DPE, Coordenação de População e Indicadores Sociais - COPIS, dados de 20102019, 2019. Disponível em: https://cidades.ibge.gov.br/brasil/pb/sousa/panorama.

IFPB. (2017). PLANO ESTRATÉGICO DE AÇÕES DE PERMANÊNCIA E ÊXITO DOS ESTUDANTES. 2017Vigência- 2017-2027. Volumes I e II. Disponível em: LINK. Acesso em: 05 dez. 2018.

IFPB. (2016). Instituto Federal de Educação Ciência e Tecnologia da Paraíba - Campus Sousa. Plano Pedagógico do Curso Técnico em Informática. Sousa: IFPB.

IFPB(2010). Plano de Desenvolvimento Institucional - PDI. Vigência 2005 - 2010. Disponível em: https://www.ifpb.edu.br/transparencia/pdi. Acesso em: 01 ago. 2018.

IFPB. (2014). Plano de Desenvolvimento Institucional - PDI. Vigência 2010 - 2014. Disponível em: https://www.ifpb.edu.br/transparencia/pdi. Acesso em: 01 ago. 2018.

IFPB. (2019). Plano de Desenvolvimento Institucional - PDI. Vigência 2015 - 2019. Disponível em: https://www.ifpb.edu.br/joaopessoa/institucional/planejamento-institucional/documentosinsitucionais/plano-de-desenvolvimento-institucional-2015_2019.pdf/view. Acesso em: 01 ago. 2018.

IFPB. (2018). Resolução ad Referendum no 25, de 21 de junho de 2018. Dispõe sobre a aprovação da reformulação da Política de Assistência Estudantil do Instituto Federal de Educação, Ciência e Tecnologia da Paraíba. MINISTÉRIO DA EDUCAÇÃO SECRETARIA DE EDUCAÇÃOPROFISSIONAL E TECNOLÓGICA INSTITUTO FEDERAL DE EDUCAÇÃO, CIÊNCIA E TECNOLOGIA DA PARAÍBA CONSELHO SUPERIOR.

KERR, C. (1982). Os Usos da Universidade. Tradução de Débora Cândida Dias Soares. Fortaleza. Edições Universidade Federal do Ceará.

SALOMON, M. F. B., SILVA, C. E. S. (2007, jul-set). A relação empresa-universidade como ferramenta estratégica a gestão de aprendizagem organizacional. GEPROS, gestão da produção, operações e sistemas. Ano 2, vol 4, p 11-22. Disponível em: https://revista.feb.unesp.br/index.php/gepros/article/view/165/113. Acesso em 09 abr. 2019.

\section{COMO CITAR ESTE ARTIGO:}

Araújo, M.S.V., Cabral Neto, A. (2020). Expansão da Educação Superior no Instituto Federal de Educação, Ciência e Tecnologia da Paraíba: os delineamentos no período 2008-2015. Holos, 36(4), 1-21. 


\section{SOBRE OS AUTORES}

\section{MAIZE SOUSA VIRGOLINO DE ARAÚJO}

Pedagoga e Mestra em Administração-Educação pela Universidade Federal da Paraíba (UFPB); Doutoranda no Programa de Pós-Graduação em Educação (PPGED-UFRN); Pedagoga do Instituto Federal de Educação, Ciência e Tecnologia da Paraíba (IFPB). E-mail: maizesousavirgolino@gmail.com

ORCID ID: https://orcid.org/0000-0003-0978-3702

\section{ANTÔNIO CABRAL NETO}

Professor Titular da Universidade Federal do Rio Grande do Norte (UFRN) e do Programa de Pós-Graduação em Educação (PPGED-UFRN); Pós-Doutor pela Universidade Federal de Pernambuco (UFPE). E-mail: acabraln@yahoo.com.br ORCID ID: https://orcid.org/0000-0001-7506-0807

Editor(a) Responsável: Francinaide de Lima Silva Nascimento

Pareceristas Ad Hoc: Anderson Costa e Lenina Silva

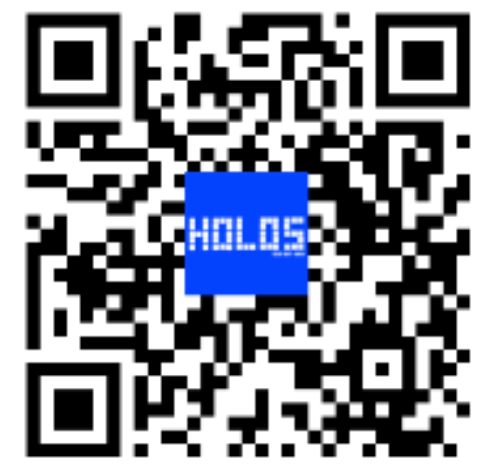

Recebido: 12 de abril de 2020 Aceito: 25 de junho de 2020 Publicado: 01 de julho de 2020 